\title{
PROFILE OF THE PATIENTS WHO UNDERWENT PROLENE HERNIA SYSTEM EXTENDED FOR INGUINAL HERNIA IN A TEACHING INSTITUTE IN SUB- HIMALAYAN REGION
}

\section{Dr Rohit Kumar}

\section{Dr Arvind Bhatia*}

MS,MO Specialist Surgery Pt Jawahar Lal Nehru Govt Medical College, Chamba, Himachal Pradesh

MS,MO Specialist Surgery Pt Jawahar Lal Nehru Govt Medical College, Chamba, Himachal Pradesh. *Corresponding Author

MBBS,Junior Resident (Biochemistry) Pt Jawahar Lal Nehru Govt Medical College, Chamba, Himachal Pradesh.

MD,Assistant Professor, Dermatology Pt Jawahar Lal Nehru Govt Medical College, Chamba, Himachal Pradesh

MD,Senior Resident, Dermatology Pt Jawahar Lal Nehru Govt Medical College, Chamba, Himachal Pradesh

MD,Senior Resident, Dermatology Pt Jawahar Lal Nehru Govt Medical College, Chamba, Himachal Pradesh

ABSTRACT Introduction: Worldwide, inguinal hernia repair is probably the most commonly performed general surgical procedure. Hence, a slight refinement of surgical repair of inguinal hernia would mean a substantial benefit to the patient. Aim: The study aimed to study profile of the patients who underwent Prolene Hernia System Extended (PHSE) for Inguinal Hernia in a teaching institute in Sub-Himalayan region. Materials and Methods: This was a controlled study conducted over 30 adult patients of both genders admitted at Dr RPGMC Tanda at Kangra from September 2016 to September 2017. Patients clinically diagnosed with inguinal hernias both direct and indirect on examination were enrolled in the trial after their informed consent. Results: Mean age of the patients was $54.9 \pm 13.66$ years (range 30 to 80 years). $33 \%$ of the patients were elderly. All the patients were males. $43 \%$ of the patients were smokers and $53 \%$ were consuming alcohol. $20 \%$ of the patients had associated co-morbidities. $7 \%$ patients had previous history of surgery. Fifty percent of the patients had direct hernia while 33\% had indirect hernia. Among 10\% patients, it was bubonocele type. Seven patients had complications. Scrotal swelling was the most common welling $(n=3)$ followed by inguinodynia $(n=2)$, and seroma formation and urinary retention in one patient each. Conclusion: PHSE for management of inguinal hernia is associated with better outcomes.

KEYWORDS : Prolene Hernia System Extended, PHSE; inguinal hernia, complications

\section{INTRODUCTION}

Inguinal hernia repair is probably the most common procedure in general surgery. It is also one of the earliest operations in a postgraduate training period of the doctors.

Inguinal hernia repairs consume an important part of health care resources because of the high incidence of the problem. It is estimated that 20 million of inguinal hernia repairs are performed globally every year. ${ }^{1}$ Every recurrence after a primary repair will add an extra cost to health care economics. Moreover, secondary or tertiary operations after previous repairs carry higher risk of re-recurrence and specific complications like testicular atrophy. Therefore, every surgeon should know and perform a current repair method successfully in his/her daily practice.

Approximately $75 \%$ of all abdominal wall hernias are seen in the groin. ${ }^{1}$ Inguinal hernia is much more common in men than women. Although femoral and umbilical hernias are more common in female population, indirect inguinal hernia is still the most common type of hernia in women. Age is a factor for incidence and type of inguinal hernia; incidence increases by age. ${ }^{2}$ Indirect hernia is more common in young and direct hernia in the elderly.

Tension-free mesh repairs for adult inguinal hernias were originally popularized by Lichtenstein et al., ${ }^{3}$ and have been popular ever since then. Combined anterior and posterior repair using Prolene ${ }^{\circledR}$ Hernia System (PHS) is a novel device developed for tension-free repair of inguinal hernia. ${ }^{4} \mathrm{PHS}$ is not a common technique in this area; hence, this study aimed to study profile of the patients who underwent PHS-extended hernia repair.

\section{METHODS}

This was a controlled study conducted over 30 adult patients of both genders admitted at Dr RPGMC Tanda at Kangra from September 2016 to September 2017. Patients clinically diagnosed with inguinal hernias both direct and indirect on examination were enrolled in the trial after their informed consent. Patients with complicated inguinal hernias (incarcerated, Strangulated), femoral hernia, children, and those unable to provide consent were excluded from the study.

Patients were informed about surgical procedure and type of anaesthesia and informed written consent was taken. Operative times (skin incision to skin closure) was recorded for each repair. Perioperative complications including iatrogenic vessel and nerve injury, seroma, hematoma, urinary retention, or wound infection, stiffness of the abdominal wall as well as anaesthesia related complication were recorded as per proforma.

Normal daily activities like walking, climbing stairs, bathing and other such activities, and time to return to normal activity was calculated.

\section{STATTISTICALL ANALYSIS}

Data were presented as frequency, percentage, mean, and standard deviation.

\section{RESULTS}

General characteristics

Table 1 shows general characteristics of the study subjects. Mean age of the patients was $54.9 \pm 13.66$ years (range 30 to 80 
years). $33 \%$ of the patients were elderly. All the patients were males. $43 \%$ of the patients were smokers and $53 \%$ were consuming alcohol. $20 \%$ of the patients had associated comorbidities. $7 \%$ patients had previous history of surgery.

\section{Type of hernia}

Fifty percent of the patients had direct hernia while $33 \%$ had indirect hernia. Among 10\% patients, it was bubonocele type (Figure 1).

\section{Post-operative pain}

We measured post-operative pain at the time of discharge on a 10-point VAS scale. Scores between 7-10, 4-6, and 1-3 were categorized as severe, moderate, and mild pain respectively. Score 0 was categorized as no pain. We observed that majority of patients $(n=16)$ had mild post-operative pain while remaining had moderate post-operative pain $(n=14)$.

\section{Complications}

Seven patients had complications. Scrotal swelling was the most common welling $(n=3)$ followed by inguinodynia $(n=2)$, and seroma formation and urinary retention in one patient each.

\section{Discussion}

The evolution of an inguinal hernias repair has gone through the phase of simple reposition, tension techniques based on Bassini's technique, and mesh techniques, open or laparoscopic [transabdominal preperitoneal (TAPP), totally extraperitoneal (TEP)]. "Plugged in" techniques are based on the insertion of synthetic, non-absorbable, semi absorbable or absorbable materials into the internal inguinal hiatus, the weak point where the indirect inguinal hernia appears. Although there has been a huge success in decrease rate of recurrences in mesh and "plug in" techniques, a new problem appears such as chronic pain, erosive complications of intraperitoneal organs and rejection of artificial material. An ideal technique for an indirect hernias repair is still not established.

Bilayer patch device (Ethicon, Prolene Hernia System ${ }^{\circledR}$ (PHS) Extended) made of polypropylene is threedimensional mesh, with two patch layers (underlay and onlay) attached to the connector in order to keep both patches stable. It has been in use for the last 20 years.

Mean age of the patients in the study was 54.9 years. In the study done by Matyja et al., the mean age of the patients was 46.7 years. ${ }^{5}$ This is comparable to other studies. ${ }^{6-8}$

All the patients in the current study were male. Male predominance was also observed in other studies. ${ }^{5,8}$

$23 \%$ of the patients in the study had complications. Postoperative scrotal swelling (10\%) was common. In other studies, incidence of the seroma formation in post op period ranged from $0.6 \%$ to $11.8 \%$.

In conclusion, PHSE offers advantage such as low pain and lesser number of complications for inguinal hernia repair.

Table 1: General characteristics

\begin{tabular}{|l|c|c|}
\hline & Frequency & Percentage \\
\hline Āge (years) & & \\
\hline $21-30$ & 1 & 3.3 \\
\hline $31-40$ & 5 & 16.7 \\
\hline $41-50$ & 6 & 20.0 \\
\hline $51-60$ & 8 & 26.7 \\
\hline $61-70$ & 6 & 20.0 \\
\hline $71-80$ & 4 & 13.3 \\
\hline Sex & & \\
\hline Male & 30 & 100 \\
\hline
\end{tabular}

\begin{tabular}{|l|c|c|}
\hline Smoking & 13 & 43.3 \\
\hline Alcohol & 16 & 53.3 \\
\hline Co-morbidities & 6 & 20 \\
\hline Previous history of surgery & 2 & 6.7 \\
\hline
\end{tabular}

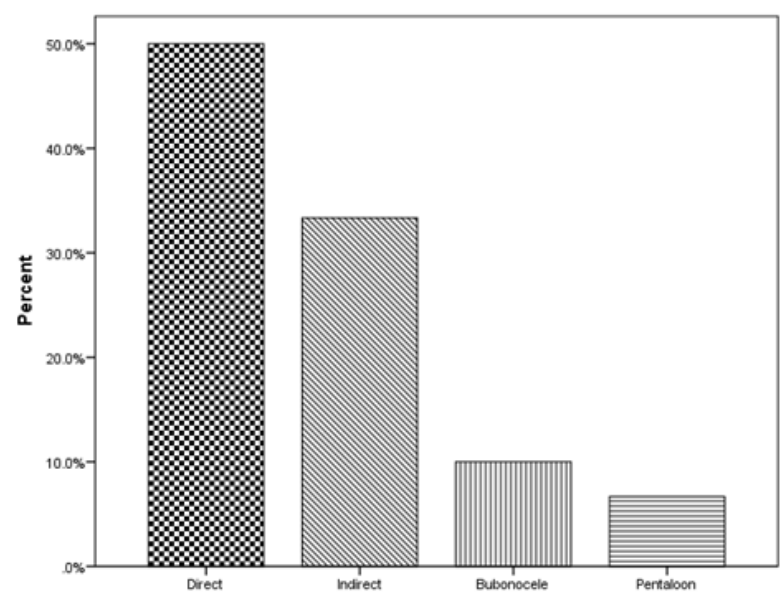

Figure 1: Type of hernia

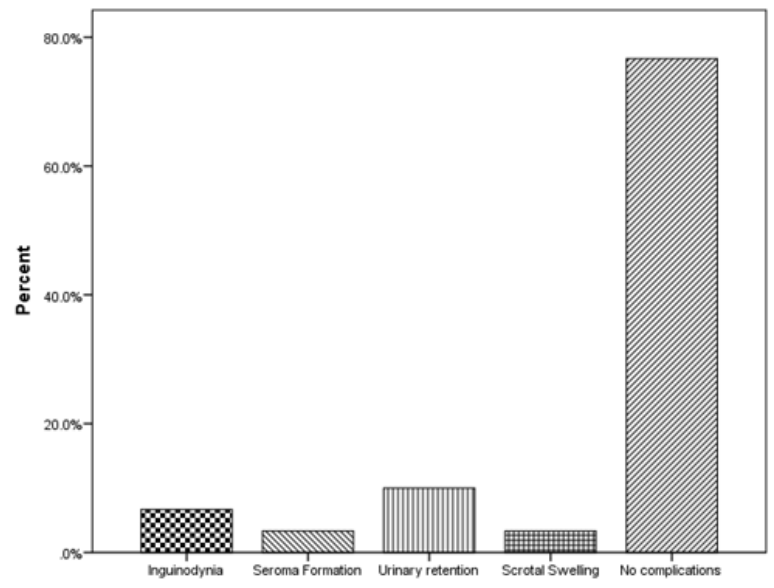

Figure 2: Complications

\section{REFERENCES}

1. Fitzgibbons RJ, Richards AT, Quinn TH. Open hernia repair. In: Souba WS, Mitchell P, Fink MP, Jurkovich GJ, Kaiser LR, Pearce WH, Pemberton JH, Soper NJ, editors. ACS Surgery: Principles and Practice. 6th ed. Philadelphia, U.S.A Decker Publishing Inc; 2002. pp. 828-849.

2. Ruhl CE, Everhart JE. Risk factors for inguinal hernia among adults in the US population. Am J Epidemiol. 2007:165:1154-1161.

3. Lichtenstein IL, Shulman AG, Amid PK, Montllor MM. The tension free hernioplasty. Am J Surg. 1989;157:188-93

4. Gilbert AI. A bilayer patch device for inguinal hernia repair. Hernia. 1999;3:161-66

5. Karaca AS, Ersoy OF, Ozkan N, Yerdel MA. Comparison of inguinal hernia repairs performed with Lichtenstein, Rutkow-Robbins, and gilbert double layer graft methods. Indian J Surg. 2015;77(1):28-33.

6. Badkur M, Garg N. Comparative Study of Prolene Hernia System and Lichtenstein Method for Open Inguinal Hernia Repair. J Clin Diagn Res 2015;9(6):PC04-7.

7. Shankar JCR, Hiregoudar AD. Comparative Study between Lichenstein Mesh Repair and Prolene Hernia System in the Management of Uncomplicated Inguinal Hernia. IJSS Journal of Surgery 2016;2(5):5-11.

8. Gohel J, Patel U. Prolene hernia system in the tension-free repair of primary inguinal hernias. Natl J Med Res 2012;2(3):302-5. 